\title{
Screening Practices among First Degree Relatives of Breast Cancer Patients in Nepal
}

Rashmi Mulmi ( $\square$ rashmi.rushme09@gmail.com )

BP Koirala Memorial Cancer Hospital https://orcid.org/0000-0002-4648-2231

\section{Gambhir Shrestha}

BP Koirala Memorial Cancer Hospital

\section{Surya Raj Niraula}

BP Koirala Institute of Health Sciences

\section{Deepak Kumar Yadav}

BP Koirala Institute of Health Sciences

\section{Paras Kumar Pokharel}

BP Koirala Institute of Health Sciences

\section{Research article}

Keywords: Breast cancer, Breast self-examination, Clinical breast examination, First degree relatives, Mammogram, Screening

Posted Date: October 18th, 2019

DOl: https://doi.org/10.21203/rs.2.16159/v1

License: (c) (i) This work is licensed under a Creative Commons Attribution 4.0 International License. Read Full License 


\section{Abstract}

Background Family history is a significant risk factor for development of breast cancer, particularly for women of first-degree relatives. For women at high risk for breast cancer, regular screening is the mainstay of risk management. This study aims to find out the breast cancer screening practices among first degree relatives of breast cancer patient and determine factors associated with their screening practices.

Methods A cross-sectional study was carried out among 150 purposively selected first-degree female relatives of breast cancer patients undergoing treatment at B.P Koirala Memorial Cancer Hospital, aged between 20 and 60 years. A semi-structured questionnaire was used to collect data by face to face interview. Screening practices were characterized as regular screening practices performed by the respondents, which include any of these screening methods: monthly breast self-examination or clinical examination yearly at least once in 3 years or regular mammogram 1 or 2 yearly. Level of awareness was categorized into two categories 'high level' and 'low level' taking median score as the cut-off value. Chisquare tests and multiple logistic regression were used to test the association between screening practices and related factors.

Results The mean age of the participants was 37.6 years (SD 10.9). A total of $38.7 \%$ had practiced regular breast screening methods. Only two-fifth of them had a high level of awareness on risk factors and warning signs of breast cancer. In multiple logistic regression, literate (OR 7.13, 95\% Cl 2.32-21.10), economic status above poverty line (OR 2.62, 95\% $\mathrm{Cl} 1.01-6.80)$, presence of benign breast disease (OR $5.10,95 \% \mathrm{Cl} 1.31-19.84$ ) and high perceived risk of breast cancer (OR 14.17, 95\% $\mathrm{Cl}$ 5.10-39.41) were found to be significant positive predictors of regular screening practices.

Conclusions This study showed a low rate of regular screening practices among the first degree relatives of breast cancer patients. There is a need to provide comprehensive, updated, and inclusive information and support and interventions aimed at increasing awareness of the importance of healthy behaviors in cancer prevention among these high-risk groups.

\section{Background}

Breast cancer constitutes a major public health issue in the world. It is the most common cancer in women worldwide with high incidence [1] and the second most common cancer overall with nearly 1.7 million new cases in 2012 representing about 12 percent of all new cancer cases and 25 percent of all cancers in women [2]. In Asia, there is a significant increase in the incidence of breast cancer among the women in reproductive age group [ 3] whereas, in the United States and Europe, it peaks among women in their sixties [4]. 
Also, in South Asia, it is detected more often in younger females and at a more advanced stage as compared to females of other regions [ 5].

Breast cancer is the second leading cancer among Nepalese women [ 6]. According to the latest WHO data published in May 2014, the age-standardized incidence rate of breast cancer was 15.24 per 100,000 and age-standardized death rate of 8.13 per 100,000. Family history of breast cancer is one of the significant risk factors for development of the disease, particularly for women with first-degree relatives diagnosed with breast cancer [ 7]. Risk of breast cancer is about 2-4 times higher for women with first-degree female relative who has been diagnosed compared to women without a family history [ 8].

American Cancer Society (ACS) recommends women in their 20s and 30s should have a clinical breast examination (CBE) as part of a periodic (regular) health exam by a health professional preferably every 3 years. Starting at age 40 , women should have a CBE by a health professional every year and should have a mammogram every year and continue to do so for as long as they are in good health [ 9]. However, the screening practices of women are depended on their awareness, attitudes, socio-demographic characteristics and cultural issues [ 10]. Breast cancer screening recommendations for women with positive family history are based on expert opinion, and typically dictate shorter screening intervals and screening beginning at an earlier age. Such strategies include annual mammographic screening beginning at age 40 years, or 10 years prior to the earliest age of onset observed in the family (whichever occurs earliest), or starting as young as age 25 years for BRCA mutation carriers [11]. Several studies have found that regular screening in women with a family history is benefitted from reporting higher cancer detection rates and favorable prognostic features of screen-detected cancers [ 11, 12]. Knowledge of risk factors for breast cancer and breast screening among women are being studied in Nepal, but none has looked at women with family history of breast cancer. This study is the first in Nepal to find out the breast cancer screening practices among first degree relatives of breast cancer patients and factors associated with it.

\section{Methods}




\section{Study setting and design}

This is a cross-sectional study carried out among first degree relatives of breast cancer patients attending B.P Koirala Memorial Cancer Hospital (BPKMCH) for their treatment form December 2016 to May 2017. BPKMCH is situated in Bharatpur, Chitwan district, Central Development Region of Nepal. It is the first national comprehensive cancer center of its kind. It is a 450 bedded hospital and provides high-quality services for the prevention, diagnosis, treatment and research on cancer, and to gain self-reliance in human resource required for the same.

\section{Inclusion criteria}

Sister, daughter, and mother of breast cancer women of age group 20 to 60 years accompanying them in the OPD, wards in $\mathrm{BPKMCH}$ were included and those with history of previous malignancies were excluded from the study.

\section{Sample size}

In a similar study done in Mexico, $38.7 \%$ of study participants had performed regular mammogram ( Bird et al., 2011). Based on the proportion, the sample size was calculated on this basis of the following formula.

Sample size $(n)=\left(Z_{1-a ́}\right)^{2} \times p q / l^{2}$

where, Z (Standard normal variate) $=1.96$ for 95\% Confidence interval.

$$
\text { Prevalence }(p)=0.39
$$

Compliment of $\mathrm{P}(\mathrm{q})=1-0.39=0.61$

Thus, at $95 \%$ confidence level and $20 \%$ of p allowable error (l), the calculated sample size was 150 .

The estimated sample size in the study was 150 participants.

\section{Methods of data collection}

The sample for the study was selected by non- probability purposive sampling method. The data were collected by the corresponding author via face-to-face interviews using semi- 
structured questionnaires examining following parts:

Part I comprised of socio-demographic characteristics, information regarding the relative (women with breast cancer) and personal medical history of the participant.

Part II comprised of level of awareness of the participant on risk factors and warning signs of breast cancer as adopted from comprehensive breast cancer knowledge test (CBCKT) with some modifications. This tool consists of 20 statements: 12 statements related to risk factors and 8 statements related to warning signs of breast cancer. Response to each statement included 'Yes', 'No' and 'Don't know'. For a correct response to any of the 20 statements on the questionnaire, a score of 1 was provided while an incorrect response or a response indicating 'Don't know' was scored 0. A composite score of all the items combined was calculated which could range from $0-20$. The median value of the composite score was 11. The level of awareness, after dichotomization taking the median as the cut-off point, was grouped into two categories: "high level" (Score $\geq 11$ ) and "low level" (Score <11).

Part III comprised of the perceived risk of developing breast cancer of the participant in their lifetime. The perceived risk was expressed in a numerical rating scale which ranges from $0 \%$ to $100 \%$, where $0 \%$ means no risk at all and 100\% means will absolutely develop cancer in future.

Part IV comprised of semi-structured questionnaires to assess the screening practices of the participants: Breast self-examination, Clinical breast examination and Mammogram practice were included in this part.

\section{Validity of the tool}

Content validity of the questionnaire was established by a literature review and consultation with concerned faculties and experts. All sets of questionnaire were translated into Nepali version and re-translated into English language in collaboration with experts. The final version was compared with old version and necessary corrections were made. Opinion from the language expert was obtained for comprehensibility and simplicity of language during language translation. Pretesting of the tool was done in $10 \%$ of the total sample size i.e. 15 samples in Bhaktapur Cancer Hospital. Necessary modifications, such as 
sequence of the questions, modification in options, simplicity of the language were done as per required.

\section{Operational definitions}

Awareness on risk factor and warning signs of breast cancer: Awareness on risk factor and warning signs was defined as high level of awareness and low level of awareness based on their correct responses to the 20 statements of CBCKT on risk factor and warning signs of breast cancer.

Breast self-examination: It refers to a regular and systemic examination of both breast and underarm areas by women visually and by palpation using her own hand on her breasts for the purpose of detecting any abnormality.

Clinical breast examination: Physical examination of the breast performed by a health care provider to check for lumps or other changes

Employment: The Occupation was classified according to Nepal Standard Classification of Occupation (NSCO-99).

Economic status: It was measured based on the measure of poverty line as defined by the World Bank. It is the minimum level of income deemed adequate in a particular country. In October 2015, the World Bank updated the international poverty line to $\$ 1.90$ a day. The economic status of the participants was classified as "below Poverty line" if per capita income $\leq$ USD 1.90 and "above Poverty line" if per capita income >USD 1.90 (1 USD = NRs 107).

First degree relatives: Mother, Daughter and Sister of blood relation with the women diagnosed with breast cancer

Level of education: Those who could not read and write were defined as illiterates. Those who could read and write or had attended at least primary level of education were defined as literates. Level of education was again classified according to Ministry of Education 
2010 as primary if Grade 1-5, Secondary if Grade 6-10 and higher secondary and above if Grade 11 and above

Perceived risk: It is the self-reported estimated risk perception of the first degree relatives to develop breast cancer. It is expressed in numerical rating scale ranging from $0 \%$ to $100 \%$ chances of developing breast cancer in their lifetime;

Screening practices: Screening practices of the participants were characterized into two variables: regular screening practices done and not done. Regular screening practices of the participants were defined as performance of any of the screening modalities: monthly breast self-examination, yearly or 2 yearly clinical breast examination and yearly or 2 yearly mammogram. The irregular performers and those who had never performed were categorized into not practiced group. Mammography and Clinical breast examination screening practice of the participants were characterized by reason and time since the last examination. Breast self-examination practice was assessed by the self-reported frequency of performance of breast cancer.

\section{Statistical analysis}

The collected data was entered, and coded in Microsoft Excel 2007 and exported into Statistical Package for Social Sciences (SPSS) version 17 for statistical analysis. The dependent variable is screening practice and independent variables are socio-demographic characteristics, number of relatives with breast cancer, relationship with the patient, presence of any breast problems, perceived risk of breast cancer, level of awareness on risk factors and warning signs of breast cancer.

Descriptive statistics (frequency, percentage, mean and standard deviation, median and inter-quartile range) were calculated along with tabular and graphical presentation. Inferential statistics was done using Chi-square test to find out the association between screening practices and socio-demographic and other related factors at 95\% confidence interval where level of significance $p=0.05$. Those variables significant at $10 \%$ level in univariate analysis were included in multiple logistic regression using backward 
elimination to find out the adjusted effects of different exploratory variables with screening practices.

\section{Ethical consideration}

The study was approved by the Institutional Review Committee (IRC), BPKIHS. Permission to conduct the study in B.P Koirala Memorial Cancer Hospital was taken from the academic department of the hospital. All the procedures were carried out after obtaining informed consent from the participants. The participants were assured about the confidentiality and anonymity of their information provided. They were informed that they have full authority to accept or refuse to take part in the study; and were also at liberty to withdraw at any time of the study. Interviews were carried out in privacy as far as possible.

\section{Results}

\section{Socio-demographic characteristics}

The mean age of the respondents was 37.6 years $(S D=10.9)$. Most of them were Hindus (68.7\%) followed by Buddhist (21.3\%). A majority (75\%) of the respondents were married. Most of the respondents belonged to nuclear family (62.0\%) and the rest belonged to joint families.

Most of the respondents were homemaker (24.7\%), followed by professional $(16.0 \%)$ and agriculture (14.7\%). Only 14\% were unemployed. Most of the respondents (68.0\%) were literate. The respondents below poverty line and above poverty line were in the ratio of 2:3. Majority of the respondents were non-insured (80.7\%). Almost half of the respondents had their mother diagnosed with breast cancer. The respondents who had their sisters diagnosed with breast cancer were $40 \%$. Only $11.3 \%$ of the respondents had their daughter suffering from breast cancer patient. The duration of breast cancer was less than one year in most of the relatives of respondents $(66.0 \%)$ whereas $34 \%$ of the relatives of respondents had duration of breast cancer one year and more. Majority of respondents (93.3\%) had only one relative with breast cancer while the rest had two relatives with breast cancer (Table 1). 


\section{Personal history}

Approximately $42.7 \%$ of the women had menarche at the age of 11 years and below. The mean age at menarche was 11.6 (SD 1.5) years. Out of 150 respondents, 112 respondents had given birth to their first child, among whom $57.1 \%$ had given birth of the first child below the age of 20 years. More than half of the respondents had good self-reported health status whereas $28 \%$ rated their health as very good. Only 4 percent of the women stated poor health status. Only 14.7 percent of the women had history of benign breast diseases. The most common benign breast disease among those women was presence of breast lump (40.9\%) which was followed by mastalgia (31.8\%). The least common benign breast disease was mastitis (9.0\%) (Table 1).

Table 1: Socio-demographic characteristics and personal medical history of the respondents $(n=150)$ 


\begin{tabular}{|c|c|c|c|}
\hline Socio-demographic Characteristics & Categories & $\begin{array}{l}\text { Frequency } \\
\text { (n) }\end{array}$ & $\begin{array}{c}\text { Percentage } \\
\text { (\%) }\end{array}$ \\
\hline \multirow[t]{4}{*}{ Age in years } & $20-29$ & 42 & 28.0 \\
\hline & $30-39$ & 42 & 28.0 \\
\hline & $40-49$ & 37 & 24.7 \\
\hline & $\geq 50$ & 29 & 19.3 \\
\hline \multicolumn{2}{|c|}{ Mean age in years \pm SD (Min-Max) } & \multicolumn{2}{|c|}{$7.6 \pm 10.9(20-60)$} \\
\hline \multirow[t]{4}{*}{ Religion } & Hindu & 103 & 68.7 \\
\hline & Buddhist & 32 & 21.3 \\
\hline & Muslim & 9 & 6.0 \\
\hline & Christian & 6 & 4.0 \\
\hline \multirow[t]{4}{*}{ Marital status } & Unmarried & 32 & 21.3 \\
\hline & Married & 109 & 72.7 \\
\hline & Divorced/Separated & 4 & 2.7 \\
\hline & Widow & 5 & 3.3 \\
\hline \multirow[t]{2}{*}{ Family type } & Nuclear & 93 & 62.0 \\
\hline & Joint & 57 & 38.0 \\
\hline \multirow[t]{7}{*}{ Occupation } & Unemployed & 21 & 14.0 \\
\hline & Agriculture & 22 & 14.7 \\
\hline & Laborer & 12 & 8.0 \\
\hline & Professional & 24 & 16.0 \\
\hline & Business & 16 & 10.7 \\
\hline & Student & 18 & 12.0 \\
\hline & Homemaker & 37 & 24.7 \\
\hline \multirow[t]{4}{*}{ Education } & Illiterate & 48 & 32.0 \\
\hline & Primary & 8 & 5.3 \\
\hline & Secondary & 47 & 31.3 \\
\hline & $\begin{array}{l}\text { Higher secondary } \\
\text { and above }\end{array}$ & 47 & 31.3 \\
\hline \multirow[t]{2}{*}{ Economic status } & Below poverty line & 60 & 40.0 \\
\hline & Above poverty line & 90 & 60.0 \\
\hline \multirow{2}{*}{$\begin{array}{l}\text { Distance between nearest health } \\
\text { facility from home }\end{array}$} & $\leq 30 \min$ & 113 & 75.3 \\
\hline & $>30 \mathrm{~min}$ & 37 & 24.7 \\
\hline \multirow[t]{2}{*}{ Medical insurance status } & Insured & 29 & 19.3 \\
\hline & Non-insured & 121 & 80.7 \\
\hline \multirow[t]{3}{*}{ Relationship with the patient } & Daughter & 17 & 11.3 \\
\hline & Mother & 72 & 48.0 \\
\hline & Sister & 61 & 40.7 \\
\hline Duration of disease & $<1$ & 99 & 66.0 \\
\hline
\end{tabular}




\begin{tabular}{|c|c|c|c|}
\hline ( in years) & $\geq 1$ & 51 & 34.0 \\
\hline \multirow[t]{2}{*}{ Number of relatives with breast cancer } & One & 140 & 93.3 \\
\hline & Two & 10 & 6.7 \\
\hline \multirow[b]{3}{*}{$\begin{array}{l}\text { Age at menarche } \\
\text { (in years) }\end{array}$} & $\leq 11$ & 64 & 42.7 \\
\hline & $>11$ & 86 & 57.3 \\
\hline & & & \\
\hline \multicolumn{2}{|c|}{ Mean age at menarche in years \pm SD (Min-Max) } & \multicolumn{2}{|c|}{$11.6 \pm 1.5(8-16)$} \\
\hline \multirow{2}{*}{$\begin{array}{l}\text { Age at first birth }(\mathrm{n}=112) \\
\text { (in years) }\end{array}$} & $\leq 20$ & 64 & 57.1 \\
\hline & $>20$ & 48 & 42.9 \\
\hline \multirow[t]{4}{*}{ Self-reported health status } & Poor & 6 & 4.0 \\
\hline & Good & 83 & 55.3 \\
\hline & Very good & 43 & 28.7 \\
\hline & Excellent & 18 & 12.0 \\
\hline \multirow{2}{*}{$\begin{array}{l}\text { Presence of benign breast disease } \\
\text { (BBD) }\end{array}$} & Yes & 22 & 14.7 \\
\hline & No & 128 & 85.3 \\
\hline
\end{tabular}

Level of awareness of the respondents on risk factors and warning signs of breast cancer

The mean score of the respondents on CBCKT score was found to be 10.8 (SD 2.8). Likewise, the median score was 11 (IQR 9-13). The level of awareness of respondents was categorized into low level and high level taking median score 11 as cut off value. The ratio of the respondents with low level of awareness to high level of awareness was found to be $2: 3$. About $54.6 \%$ of the respondents perceived their risk of developing breast cancer in their lifetime as 50\% and above (Table 2).

Table 2: Level of awareness on risk factors and warning signs of breast cancer and perceived risk of developing breast cancer of respondents $(n=150)$ 


\begin{tabular}{|l|c|c|}
\hline Variables & Frequency (n) & Percentage (\%) \\
\hline Level of awareness & & \\
\hline Low level & 60 & 40 \\
\hline High level & 90 & 60 \\
\hline Perceived risk & & \\
\hline$<50 \%$ & 68 & 45.4 \\
\hline $50 \%$ and more & 82 & 54.6 \\
\hline
\end{tabular}

\section{Practice of breast screening methods}

Majority of the respondents had heard about the breast cancer screening methods. Selfbreast examination (88\%) was the most common screening method familiar within the respondents. Mammography was the least heard screening method. A total of 116 (77.3\%) women had ever practiced breast self-examination (regular $=34.7 \%$, irregular $=42.7 \%$ ) and 42 (28.0\%) had ever practiced clinical breast examination (regular=14.7\%, irregular $=13.3 \%$ ). Only 10 percent of the women had performed mammogram regularly as recommended. Majority of the respondents had never practiced mammogram. The practice of mammogram was further analyzed among the respondent aged 40 above years, as it is recommended after the age 40 years. Thus, the overall practice of mammogram among the eligible age group was found to be 18 (27.3\%). However, one woman had performed at the age of 35 years. Overall screening practices were characterized as regular screening practices performed by the respondents which include any of these screening methods: monthly breast self-examination or clinical breast examination yearly or 2-3 yearly or regular mammogram 1 or 2 yearly. Thus, the women who had practiced regular screening were 58 (38.7\%) (Table 3).

Table 3: Breast screening practices among the respondents

Regular screening practices and socio-demographic characteristics 


\begin{tabular}{|c|c|c|c|c|c|}
\hline Regular & Breast screening Practices & Heard & \multicolumn{3}{|c|}{ Practice } \\
\hline & & & Regular & Irregular & Never \\
\hline \multirow{3}{*}{$\begin{array}{l}\text { screening } \\
\text { practices }\end{array}$} & Self-examination & $132(88.0)$ & $52(34.7)$ & $64(42.7)$ & $34(22.6)$ \\
\hline & Clinical examination & $109(72.7)$ & $22(14.7)$ & $20(13.3)$ & $108(72)$ \\
\hline & Mammogram & $105(70.0)$ & $15(10.0)$ & $4(2.7)$ & $131(87.3)$ \\
\hline nong & Overall screening practice & - & $58(38.7)$ & \multicolumn{2}{|c|}{$92(38.7)$} \\
\hline
\end{tabular}

younger age

group (OR=3.13) was more than the older age group ( $50 \%$ vs $24.2 \%)$ and this difference was found to be significant $(p=0.001)$. Similarly, more literate women had regular screening practices compared to that of illiterate women (51.0\% vs $12.5 \%$ ) which was highly significant $(\mathrm{p}<0.001)$. The association was found to be significant with economic status in regards to poverty line, $(\mathrm{p}<0.001)$. Regular screening practices were found more in ever-married women than unmarried women (39\% vs $37.5 \%$ ). However, this difference was not found to be statistically significant. Likewise, no significant association of regular screening practices was found with occupation, and distance between nearest health facility and residence. Majority of women (72.4\%) with insurance regularly practiced regular breast screening than women without insurance (30.6\%) and this difference was found be statistically significant $(\mathrm{p}<0.001)$. The number of relatives with breast cancer were not found to be statistically significant with the screening practices. the respondents whose mother were diagnosed with breast cancer were 7.69 times more likely to have regular screening than those having daughter as patient. This difference was found to be statistically significant. Likewise, the duration of disease of the relatives was also found to be statistically significant $(\mathrm{p}=0.001)$. women with history of benign breast disease were found to practice regular screening 5.56 times more likely than those without benign breast disease $(72.7 \%$ vs $32.8 \%$ ) and this difference was found to be statistically significant $(p<0.001)$. Regular screening was found to be more among women with no history of chronic illness than their counterparts (40.7\% vs $29.6 \%)$. However, this difference was not found to be statistically significant $(\mathrm{p}=0.287)$. As illustrated in table 22 , women with history of benign breast disease were found to practice regular screening 5.56 times more likely than those without benign breast disease $(72.7 \%$ vs $32.8 \%)$ and this difference was found to be statistically significant $(\mathrm{p}<0.001)$. Regular screening was found to be more among 
women with no history of chronic illness than their counterparts (40.7\% vs 29.6\%). However, this difference was not found to be statistically significant $(p=0.287)$. The respondents who had heard about hereditary breast cancer were found to be regularly practicing breast screening than their counterpart (47.9\% vs 3.2\%) and this difference was found to be highly significant $(\mathrm{p}<0.001)$ (Table 4).

Table 4: Association of regular screening practices with socio-demographic characteristics and personal history of the respondents $(n=150)$ 


\begin{tabular}{|c|c|c|c|c|c|}
\hline \multirow[t]{2}{*}{$\begin{array}{l}\text { Socio-demographic } \\
\text { Characteristics }\end{array}$} & \multicolumn{2}{|c|}{$\begin{array}{c}\text { Regular screening } \\
\text { practices }\end{array}$} & \multirow[t]{2}{*}{ OR } & \multirow[t]{2}{*}{$95 \%$ CI } & \multirow[t]{2}{*}{ p-value } \\
\hline & $\begin{array}{l}\text { Yes n } \\
(\%)\end{array}$ & No $n(\%)$ & & & \\
\hline $\begin{array}{l}\text { Age } \\
<40 \text { years } \\
\geq 40 \text { years }\end{array}$ & $\begin{array}{l}42 \\
(50.0) \\
16 \\
(24.2)\end{array}$ & $\begin{array}{l}42(50.0) \\
50(75.8)\end{array}$ & $\begin{array}{c}\text { Ref } \\
3.13\end{array}$ & $1.54-6.34$ & 0.001 \\
\hline $\begin{array}{l}\text { Level of education } \\
\text { Illiterate } \\
\text { Literate }\end{array}$ & $\begin{array}{r}6(12.5) \\
52(51.0)\end{array}$ & $\begin{array}{l}42(87.5) \\
50(49.0)\end{array}$ & $\begin{array}{l}\text { Ref } \\
7.14\end{array}$ & $2.86-16.68$ & $<0.001$ \\
\hline $\begin{array}{l}\text { Economic status } \\
\text { Below poverty line } \\
\text { Above poverty line }\end{array}$ & $\begin{array}{l}12 \\
(20.0) \\
46 \\
(51.1)\end{array}$ & $\begin{array}{l}48(80.0) \\
44(48.9)\end{array}$ & $\begin{array}{l}\text { Ref } \\
4.17\end{array}$ & $1.96-9.09$ & $<0.001$ \\
\hline $\begin{array}{l}\text { Occupation } \\
\text { Unemployed } \\
\text { Employed }\end{array}$ & $\begin{array}{l}17 \\
(29.3) \\
41 \\
(44.6)\end{array}$ & $\begin{array}{l}41(70.7) 51 \\
(55.4)\end{array}$ & $\begin{array}{l}\text { Ref } \\
1.92\end{array}$ & $0.96-3.85$ & 0.062 \\
\hline $\begin{array}{l}\text { Marital status } \\
\text { Unmarried } \\
\text { Ever married }\end{array}$ & $\begin{array}{c}12 \\
(37.5) \\
46 \\
(39.0)\end{array}$ & $\begin{array}{l}20(62.5) \\
72(61.0)\end{array}$ & $\begin{array}{l}\text { Ref } \\
1.06\end{array}$ & $0.47-2.28$ & 0.879 \\
\hline $\begin{array}{l}\text { Insurance } \\
\text { Non-Insured } \\
\text { Insured }\end{array}$ & $\begin{array}{c}37 \\
(30.6) \\
21 \\
(72.4)\end{array}$ & $\begin{array}{r}84(69.4) \\
8(27.6)\end{array}$ & $\begin{array}{l}\text { Ref } \\
5.88\end{array}$ & $2.44-14.29$ & $<0.001$ \\
\hline $\begin{array}{l}\text { Duration of disease } \\
<1 \text { year } \\
\geq 1 \text { year }\end{array}$ & $\begin{array}{l}29 \\
(29.3) \\
29 \\
(56.9)\end{array}$ & $\begin{array}{l}70(70.7) \\
22(43.1)\end{array}$ & $\begin{array}{l}\text { Ref } \\
3.22\end{array}$ & $1.56-6.25$ & 0.001 \\
\hline $\begin{array}{l}\text { Relationship } \\
\text { Daughter } \\
\text { Mother }\end{array}$ & $2(11.8)$ & $\begin{array}{l}15(88.2) \\
35(48.6)\end{array}$ & $\begin{array}{c}\text { Ref } \\
7.69\end{array}$ & $0.06-1.42$ & 0.003 \\
\hline
\end{tabular}




\begin{tabular}{|c|c|c|c|c|c|}
\hline Sister & $\begin{array}{l}37 \\
(51.4) \\
19 \\
(31.1)\end{array}$ & 42 (68.9) & 3.33 & $0.70-16.67$ & 0.111 \\
\hline $\begin{array}{l}\text { No. of relatives with breast } \\
\text { cancer } \\
\text { One } \\
\text { Two }\end{array}$ & $\begin{array}{l}53 \\
(37.9) \\
5 \\
(50.0)\end{array}$ & $\begin{array}{r}87(62.1) \\
5(50.0)\end{array}$ & $\begin{array}{l}\text { Ref } \\
1.64\end{array}$ & $0.46-5.88$ & 0.446 \\
\hline $\begin{array}{l}\text { Presence of chronic diseases } \\
\text { Yes } \\
\text { No }\end{array}$ & $\begin{array}{l}8 \\
(29.6) \\
50 \\
(40.7)\end{array}$ & $\begin{array}{l}19(70.4) \\
73(59.3)\end{array}$ & $\begin{array}{l}\text { Ref } \\
1.61\end{array}$ & $0.66-4.00$ & 0.287 \\
\hline $\begin{array}{l}\text { Personal history of benign } \\
\text { breast disease } \\
\text { No } \\
\text { Yes }\end{array}$ & $\begin{array}{l}42 \\
(32.8) \\
16 \\
(72.7)\end{array}$ & $\begin{array}{c}86(67.2) \\
6(27.3)\end{array}$ & $\begin{array}{c}\text { Ref } \\
5.55\end{array}$ & $2.00-14.29$ & $<0.001$ \\
\hline $\begin{array}{l}\text { Know about hereditary breast } \\
\text { cancer } \\
\text { No } \\
\text { Yes }\end{array}$ & $\begin{array}{l}1(3.2) \\
57 \\
(47.9)\end{array}$ & $\begin{array}{l}30(96.8) \\
62(52.1)\end{array}$ & $\begin{array}{c}0.04 \\
\text { Ref }\end{array}$ & $0.01-0.26$ & $<0.001$ \\
\hline
\end{tabular}

Regular screening practices and level of awareness and perceived risk of breast cancer

Women with high level of awareness on risk factors and warning signs of breast cancer were found to practice regular screening more than those with poor level of awareness; ( $58.3 \%$ vs $25.6 \%)$ this difference was found to be statistically significant $(p<0.001)$. Women who perceived their risk of acquiring breast cancer in the future $50 \%$ or more were found to practice regular screening more $(\mathrm{OR}=16.67)$ than those who perceived less than $50 \%$ risk $(63.4 \%$ vs $8.8 \%)$ and this difference was found to be highly significant $(0<0.001)$ (Table $5)$. 
Table 5: Association of regular screening practices with level of awareness and perceived risk of breast cancer $(n=150)$

\begin{tabular}{|l|c|c|c|c|c|}
\hline \multirow{2}{*}{ Characteristics } & \multicolumn{2}{|c|}{ Regular screening practices } & OR & 95\% CI & p-value \\
\cline { 2 - 3 } & Yes n (\%) & No n (\%) & & & \\
\hline Level of Awareness & $23(25.6)$ & $67(74.4)$ & Ref & & \\
Low & $35(58.3)$ & $25(41.7)$ & 4.00 & $2.04-8.33$ & $<0.001$ \\
High & $6(8.8)$ & $62(91.2)$ & Ref & & \\
\hline Perceived risk & $52(63.4)$ & $30(36.6)$ & 16.67 & $7.14-50.00$ & $<0.001$ \\
$<50 \%$ & & & & & \\
$\geq 50 \%$ & &
\end{tabular}

Regular screening practices and related variables

Those variables which were significant at $10 \%$ level in univariate analysis were further analyzed in multiple logistic regression with backward regression to yield the final predictors for regular screening practices among the first degree relatives. Final regression model showed level of education, economic status, presence of benign breast disease and perceived risk were significantly associated factors with regular breast screening practices. Literate women were almost 7 times more likely to practice regular screening than illiterate women. Likewise, the odds ratio of regular screening practices in women above poverty line to that of women below poverty line was found to be 2.62 (CI: $1.01-6.80$ ). The female who had history of benign breast disease were almost 5 times more likely to perform regular screening than the women without benign breast diseases. Further, the perceived risk of developing breast cancer was also found to be important predictor in regular performance of breast cancer screening (OR=14.17, CI: 5.10-39.41) (Table 6).

Table 6: Multiple logistic regression of regular screening practices with related variables $(\mathrm{n}=150)$ 


\begin{tabular}{|l|c|c|c|}
\hline \multirow{2}{*}{ Variables } & \multicolumn{3}{|c|}{ Backward regression model } \\
\cline { 2 - 4 } & Adjusted OR & $95 \%$ CI & p-value \\
\hline Level of education & Ref & & \\
Illiterate & 7.13 & $2.32-21.10$ & 0.001 \\
Literate & & & \\
\hline Economic status & Ref & & \\
Below poverty line & 2.62 & $1.01-6.80$ & $\mathbf{0 . 0 4 7}$ \\
Above poverty line & & & \\
\hline Presence of benign breast disease & Ref & & \\
No & 5.10 & $1.31-19.84$ & $\mathbf{0 . 0 1 9}$ \\
Yes & & & \\
\hline Heard about hereditary breast cancer & Ref & & \\
No & 4.02 & $0.97-16.67$ & 0.055 \\
Yes & & & \\
\hline Perceived risk & & & \\
$<50 \%$ & Ref & & \\
$\geq 50 \%$ & 14.17 & $5.10-39.41$ & $<0.001$ \\
\hline
\end{tabular}

\section{Discussion}

The first degree relatives of breast cancer are in greater risk of developing breast cancer. This is the first study in Nepal, to the best of our knowledge, to investigate the screening practices among the first degree relatives of breast cancer. Early menarche is one of the risk factors of breast cancer, thus finding of the study shows that 42.7 percent of the women are exposed to one of the risk factors of breast cancer [ 13]. Only 14.7 percent of the respondents had history of benign breast disease, which was similar to the finding in another study done in Philippines [ 14]. Women with a family history of breast cancer are more likely to develop benign breast disease and are also at increased risk for developing high-risk types of BBD such as atypical hyperplasia [ 11].

More than half of the respondents were aware of the risk factors like early menarche, delayed menopause, positive family history and also the protective role of breastfeeding and exercise. In another study done in Nepal, awareness on these risk factors was found to be low in contrast to the above findings of the present study [15]. The reason behind this 
contrasting result could be, in the present study only first-degree female relatives of breast cancer patients were considered whereas, in another study, the participants were general population. As our study group is a risk group they might have enquired about the disease and may have gained knowledge.

In the present study, majority of the respondents were aware of screening procedures. The self-breast examination was the most known screening procedure among the respondents and mammogram was the least known. This finding correlates with the result of the study done in Malaysia [ 16]. On the other hand, in a study done in Nepal among the female residents of Pokhara valley, more than half of the respondents were unaware of clinical breast examination and mammogram [ 5]. This suggests that compared to general population, these high-risk group women are more aware of the screening procedures. Nevertheless, every woman should have access to information on screening modalities.

The present study reveals that majority (77.3\%) of the respondents had ever performed breast self-examination. Likewise, in Nigeria, 61.4 percent of the first degree relatives of breast cancer had ever performed breast self-examination [ 17]. The women who had practiced monthly breast self-examination account for 34.7 percent of women among total respondents. On the other hand, in various studies done among the women without positive family history of breast cancer, the proportion of women performing breast selfexamination in regular basis was found to be lower than the finding of the present study i.e. 15 percent in India, 10.2 percent in Iran and 17 percent in Nepal respectively [ 9, 10, 18].

As in the present study, the proportion of women conducting breast self-examination was high; however the regular performers were rather low. Similarly, in another study, 92.6 percent of the women had ever performed BSE but, only 30.1 percent of the women were the regular performers [ 19]. In the present study, majority of the respondents had not performed clinical breast examination and only 4.8 percent had done annually. This finding was in accordance with those reported in a study by Tilaki in Iran in which 74.5 percent of the women had never visited for clinical breast examination and only 8.4 percent of the women performed annually [ 10]. In contrast to above findings, in previous studies done 
among women with positive family history, 84 percent of the respondents had reported of performing clinical breast examination [ 20, 21].

Only 12.7 percent of the women had ever performed mammogram at least once in their lifetime. This finding was likely similar to the finding of another study done in Malaysia in which 19.1 percent of women had practiced mammogram [ 16]. Likewise, the practice of doing mammogram was found to be similar in another study done in Nepal among women with no positive family history of breast cancer [22]. Oppositely, the rate of screening mammography above age 40 years was reported to be quite higher than the result of the present study done in similar study done in USA [23]. This shows the vast difference in screening practice of Nepalese women and American women. This might be because of difference in female literacy rate of the two countries and the facility of mammogram in the health center. In Nepal, mammogram facility is not easily available in all health centers.

A significant association of screening practices with socio-demographic characteristics of the respondents was found in this study: age of the respondents, level of education, economic status, occupation, and insurance were found to be associated with regular screening practices of the respondents. In a study done in Iran, significant association between age of women and education level with regular practice of screening was found [ 10]. This study shows that older age women have more compliance with regular screening in comparison to their counterpart. Breast cancer in young Nepalese women represents over one-quarter of all female breast cancers, many being diagnosed at an advanced stage [ 24]. Thus, it is important to aware young women to perform regular screening. Also literacy was found to be one of the important predictors for regular screening practices. Literate women are found to be more aware regarding the screening methods and also are familiar with the screening guidelines thus; they seem to be more conscious in the performance of screening. In a similar study done in Malaysia, income was found to be significantly associated with practices of BSE and mammogram among the participants [ 16]. In this study, the respondents had cited mammogram being too expensive to perform as one of the reasons for not performing it. Mammogram facility should be easily available in the hospitals and the cost should also be made affordable. Likewise, in a study done in 
Taiwan, women who had insurance coverage were more likely to perform regular screening practices [25].

Longer the duration of disease of relatives, the more is the practice of regular screening was seen in this study. This might be because the respondents who had their relatives diagnosed with breast cancer for a longer period ( $\geq 1$ year) are more experienced with the severity of disease, economic burden and poor quality of life of the patient. This exposure of the women could have made them more conscious about the disease leading to regular practice of screening. The women who had their mother diagnosed with breast cancer were more likely to perform regular screening practices to those who had daughter or sister diagnosed with breast cancer. This result was consistent with the finding of another study in which the daughters of breast cancer patients were more likely to perform regular screening [ 7]. However, in another study done in Malaysia, women who had mother diagnosed with breast cancer were unlikely to perform screening [ 16].

Presence of benign breast disease and other breast problem among the respondents was found to be an important determinant for performing regular screening. In a study done by Abbaszadeh et al showed that the women who had benign breast disease had high perceived sensitivity; the study showed that perceived sensitivity was positively related to the screening practices [26]. Contrarily, presence of benign breast disease and screening practices was found independent in another study [27]. The women who have breast problem are more conscious and may have perceived the risk of breast cancer more so that their compliance with screening is regular.

Perceived risk of breast cancer was found to be predictor for breast cancer screening practices similar to other studies [28]. A meta-analysis reported that women with a family history of breast cancer as higher than other women and found positive association between higher perceived risk and mammography screening [29].

Regular screening practices were influenced by the level of awareness on risk factors and warning signs of breast cancer in this study similar to the findings of other studies [ 10, 30]. However, in a study done by Karma; level of awareness and screening practices were 
found to be independent of each other [27]. Thus, this shows that there is need for proper counseling to the women for screening despite their high level of awareness.

In the current study, regular screening practices of the respondents are influenced by their familiarity with hereditary breast cancer. The screening uptake was higher among the women who were counseled about hereditary breast cancer [31].

Various modifiable and non-modifiable risk factors of breast cancer have been studied so far. Family history is one important non-modifiable risk factor. Therefore, adherence to screening methods is crucial for early detection and better prognosis. Paradoxically, a large proportion of women with a family history of breast cancer do not make use of available screening methods. Moreover, irregular screening practices and poor competency in performing self-breast examination could miss the chance of early detection of cancer leading to late-stage presentation. This puts a high burden on the already overburdened healthcare services. Awareness of different screening modalities should be raised among these women. Future studies should try to explore the lived experiences of women with positive family history of breast cancer, using qualitative approach. This will help to understand better how the family experience influences their practice of breast screening.

There are some limitations to the study. First, the data was collected from one hospital and non-probability sampling was used, thus this study cannot be generalized. However, the chosen hospital is the largest and nationally representative cancer hospital where $50 \%$ of the cancer cases from around Nepal are treated. Furthermore, this study does not allow us to make definitive inferences about the effect of risk factors associated with screening practices, as it has a cross-sectional design and this study used self-reported data.

\section{Conclusions}

Screening practices among the first degree relatives of breast cancer patients were found to be low in the present study. Likewise, the level of awareness on risk factors and warning signs of breast cancer was also found to be low among the respondents. Health care providers should provide these women opportunities to discuss their thoughts and experiences with breast cancer. There is a need to provide comprehensive, updated, and 
inclusive information and support and interventions aimed at increasing awareness of the importance of healthy behaviors in cancer prevention among these high-risk groups. Future studies should try to explore the lived experiences of women with positive family history of breast cancer, using qualitative approach. This will help to understand better how the family experience influences their practice of breast screening.

\section{Abbreviations}

$\begin{array}{ll}\text { ACS } & \text { American Cancer Society } \\ \text { AOR } & \text { Adjusted Odds Ratio } \\ \text { BPKMCH } & \text { B.P. Koirala Memorial Cancer Hospital } \\ \text { CBE } & \text { Clinical breast examination } \\ \text { CBCKT } & \text { Comprehensive Breast Cancer Knowledge Test } \\ \text { CI } & \text { Confidence Interval } \\ \text { OR } & \text { Odds ratio } \\ \text { SD } & \text { Standard Deviation } \\ \text { WHO } & \text { World Health Organization }\end{array}$

\section{Declarations}

\section{Acknowledgements}

We express our gratitude to the B.P. Koirala Memorial Cancer Hospital for giving us permission to conduct this study. We are thankful to all the participants who helped us and participated in the study.

\section{Funding}

None

\section{Availability of data and materials}

The datasets used and/or analyzed during the current study are available from the corresponding author upon reasonable request.

\section{Authors' Contributions}


RM, SRN, DKY and PKP designed the study. RM, SRN, DKY and PKP were responsible for streamlining the research idea and finalizing the questionnaire. RM and GS collected the data. RM, SRN and GS were involved in data cleaning and statistical analysis. All authors contributed to the interpretation of the results. RM wrote the preliminary drafts. All authors have read and approved the final version of the manuscript.

Competing Interests

The authors declare that they have no competing interests.

Consent for publication

Not applicable

\section{Ethical approval and consent to participate}

The study was reviewed and approved by Institutional Ethical Review Board, B.P Koirala Institute of Health Sciences. All participants gave written informed consent prior to the interview.

\section{References}

Fitzmaurice C, Dicker D, Pain A, Hamavid H, Moradi-Lakeh M, MacIntyre MF, Allen C, Hansen G, Woodbrook R, Wolfe C: The global burden of cancer 2013. JAMA oncology 2015, 1(4):505-527.

Ferlay J, Soerjomataram I, Ervik M: GLOBOCAN, cancer incidence and mortality worldwide: IARC cancer base no. 11 [Internet]. Lyon, France: International Agency for Research on Cancer; 2013. In.; 2012.

Simonsen K: Breast Cancer Knowledge and Attitudes Among Women in Armenia. The University of Utah; 2013.

Khokhar A: Breast cancer in India: where do we stand and where do we go? Asian Pacific Journal of Cancer Prevention 2012, 13(10):4861-4866. 
Bhatt V, Wetz R, Shrestha R, Shrestha B, Shah N, Sayami P, Gurung C, Weiserbs K: Breast cancer knowledge, attitudes and practices among Nepalese women. European journal of cancer care 2011, 20(6):810-817.

Sharma A, Zhang J: Depression and its predictors among breast cancer patients in Nepal. ASEAN Journal of Psychiatry 2014, 16(1):106-115.

Ormseth SR: Screening Adherence and Emotional Adjustment of Daughters of Breast Cancer Patients. Screening 2013, 9:1-2013.

Cancer CGoHFiB: Familial breast cancer: collaborative reanalysis of individual data from 52 epidemiological studies including 58209 women with breast cancer and 101986 women without the disease. The lancet 2001, 358(9291):1389-1399.

Shrestha K: Breast cancer knowledge and screening practice among women visited to KIST medical college. Nepal Med Coll J 2012, 14(4):308-311.

Tilaki KH, Auladi S: Awareness, Attitude, and Practice of Breast Cancer Screening Women, and the Associated Socio-Demographic Characteristics, in Northern Iran. Iranian journal of cancer prevention 2015, 8(4).

Walker MJ: Breast Cancer Screening Behaviours and Outcomes in Women with a Family History of Breast and/or Ovarian Cancer in Ontario. University of Toronto; 2014.

Kartal M, Ozcakar N, Hatipoglu S, Tan MN, Guldal AD: Breast cancer risk perceptions of Turkish women attending primary care: a cross-sectional study. BMC women's health 2014, 14(1):1.

Breast Cancer Facts \& Figures 2015-2016. www.cancer.org/acs/groups/content/.../acspc-046381.pdf]

Kashiwagi Y, Kakinohana S: Breast Cancer Knowledge and Preventive Behavior Among Filipino Women in a Rural Area: A Cross-Sectional Study. Nursing and Midwifery Studies 2016, 5(3).

Bhandari PM, Thapa K, Dhakal S, Bhochhibhoya S, Deuja R, Acharya P, Mishra SR: Breast cancer literacy among higher secondary students: results from a cross-sectional study in Western Nepal. BMC cancer 2016, 16(1):1.

Subramanian P, Oranye NO, Masri AM, Taib NA, Ahmad N: Breast cancer knowledge and screening behaviour among women with a positive family history: a cross sectional study. 
Asian Pacific Journal of Cancer Prevention 2013, 14(11):6783-6790.

Adelekan AL, Edoni ER: Awareness, Knowledge and Practices of Breast Cancer Prevention among Women with Family History of Breast Cancer in Ede, Osun State, Nigeria. Age (years) 2012, 25(34):35-44.

Ahuja S, Chakrabarti N: To determine the level of knowledge regarding breast cancer and to increase awareness about breast cancer screening practices among a group of women in a tertiary care hospital in Mumbai, India. Int J Public Health 2010, 1(1).

Erdem Ö, Toktaş İ: Knowledge, attitudes, and behaviors about breast self-examination and mammography among female primary healthcare workers in Diyarbakır, Turkey. BioMed research international 2016, 2016.

Tunin R, Uziely B, Woloski-Wruble AC: First degree relatives of women with breast cancer: who's providing information and support and who'd they prefer. PsychoOncology 2010, 19(4):423-430.

Bird Y, Moraros J, Banegas MP, King S, Prapasiri S, Thompson B: Breast cancer knowledge and early detection among Hispanic women with a family history of breast cancer along the US-Mexico border. Journal of health care for the poor and underserved 2010, 21(2).

Sathian B, Nagaraja SB, Banerjee I, Sreedharan J, De A, Roy B, Rajesh E, Senthilkumaran S, Hussain SA, Menezes RG: Awareness of breast cancer warning signs and screening methods among female residents of Pokhara valley, Nepal. Asian Pacific Journal of Cancer Prevention 2014, 15(11):4723-4726.

Hibler L: Screening Mammography Among Women With A Family History Of Breast Cancer. 2014.

Thapa B, Singh Y, Sayami P, Shrestha UK, Sapkota R, Sayami G: Breast cancer in young women from a low risk population in Nepal. Asian Pacific Journal of Cancer Prevention 2013, 14(9):5095-5099.

Wu T-Y, Chung S, Yeh M-C, Chang S-C, Hsieh H-F, Ha SJ: Understanding breast cancer screening practices in Taiwan: a country with universal health care. Asian Pacific Journal of Cancer Prevention 2012, 13(9):4289-4294. 
Abbaszadeh A, Haghdoost A, Taebi M, Kohan S: The relationship between women's health beliefs and their participation in screening mammography. Asian Pac J cancer prev 2007, 8(4):471-475.

Rabon-Stith KM: The Relationship Between Select Variables and the Breast Cancer Screening Practices of a Convenient Sample of African-American Women From Grambling State University and the Willis-Knighton Neighborhood Clinic. Virginia Tech; 2001.

Zhang LR, Chiarelli AM, Glendon G, Mirea L, Edwards S, Knight JA, Andrulis IL, Ritvo P: Influence of perceived breast cancer risk on screening behaviors of female relatives from the Ontario site of the Breast Cancer Family Registry. European journal of cancer prevention: the official journal of the European Cancer Prevention Organisation (ECP) 2011, 20(4):255.

Katapodi MC, Lee KA, Facione NC, Dodd MJ: Predictors of perceived breast cancer risk and the relation between perceived risk and breast cancer screening: a meta-analytic review. Preventive medicine 2004, 38(4):388-402.

Komenaka IK, Nodora JN, Hsu C-H, Martinez ME, Gandhi SG, Bouton ME, Klemens AE, Wikholm LI, Weiss BD: Association of health literacy with adherence to screening mammography guidelines. Obstetrics \& Gynecology 2015, 125(4):852-859.

Elobaid YE, Aw TC, Grivna M, Nagelkerke N: Breast cancer screening awareness, knowledge, and practice among Arab women in the United Arab Emirates: a cross-sectional survey. PloS one 2014, 9(9):e105783. 